\title{
Solar Operated Weather Forecasting Station
}

\author{
Prof. Vinaya K Thombare. \\ Electrical Engineering \\ Ashokrao Mane Group of Institution, \\ Vathar, INDIA \\ vkt@amgoi.edu.in \\ Sudhir D Patil \\ Electrical Engineering \\ Ashokrao Mane Group of Institution, \\ Vathar, INDIA \\ sudhirpati1780@gmail.com
}

\author{
Vasim I Khan. \\ Electrical Engineering \\ Ashokrao Mane Group of Institution, \\ Vathar, INDIA \\ khanvasim8366@gmail.com \\ Prafull S Koli \\ Electrical Engineering \\ Ashokrao Mane Group of Institution, \\ Vathar, INDIA \\ prafullkoli23@gmail.com
}

\author{
Gaurav R Kapale \\ Electrical Engineering \\ Ashokrao Mane Group of Institution, \\ Vathar, INDIA \\ gauravkapale1010@gmail.com \\ Shubham R Jadhav \\ Electrical Engineering \\ Ashokrao Mane Group of Institution, \\ Vathar, INDIA \\ shubhj.3737@gmail.com
}

\begin{abstract}
The electrical energy generated by PV systems depends mainly on the available solar radiation reaching the PV modules. Tracking systems ensure that the sun's rays fall perpendicular on the active surface of the PV module. Improving the efficiency of solar panels is the main task of solar energy generation. One of the methods is a solar tracking system. The most critical parameters of tracking systems is a precise orientation to the sun. This paper presents the outline and execution of a simple, easy and cheaper automatic, Aurdino based single-axis solar tracking for weather forecasting station application.
\end{abstract}

In this paper, single-axis solar trackers' performance based on schedule and light-dependent resistor (LDR) photosensors and a stationary photovoltaic installation in various weather conditions has compared. A comparative analysis of the operation of a manufactured schedule solar tracker and an LDR solar tracker in different weather conditions for one year has performed; also, a simple method for determining the rotation angle of a solar tracker based on the encoder has proposed.

\section{INTRODUCTION}

Climate change and the exponential growth of energy demand are calling for a huge expansion of renewable energy sources around the world. Currently, the installed capacity of all photovoltaic systems (PV) worldwide is greater than the sum of all other renewable energy systems [1]. Many research study focus on designing and developing efficient and reliable solar power systems. To improve and optimize efficiency on solar energy absorption, solar tracking system and control have been becoming one of the most important components on the solar power system [2]. The main goal of tracking systems is to increase the energy yield, which according to previously conducted research and studies ranges between $22 \%$ and $56 \%$ compared to a fixed solar system. However, it also depends on the driving system, degree of freedom, control system, and other parameters such as weather conditions or location. The generated electrical energy from photovoltaic systems depends mainly on solar radiation reaching the photovoltaic modules, as well as the materials used the temperature and the inverter [1]

Modern agriculture has focused on weather forecasting and knowledge of meteorological parameters. The use of science and technology to predict the atmosphere for a specific location is known as weather forecasting. Farmers and agricultural experts may use weather forecasting systems to collect data on various weather parameters (temperature, humidity, moisture, and leaf wetness value, for example). It forecast precise timing for various farming activities based on real-time and historical data. Chemical protection and frost protection are two primary practices that influenced by weather conditions. These two conditions will drastically reduce or even eliminate the number of products produced in a single production year. However, with the proper care at the right time, the above issues have effectively prevented [3].

This paper presents one method for establishing a private weather station. This paper aims to measure and acquire the weather data parameters like temperature, pressure, humidity, wind direction, wind speed, and solar radiation at a given site for setting up an astronomical observatory. These weather parameters with other data help to determine the potentially suitable place for astronomical seeing. The proposed weather data acquisition system works as an autonomous instrument. To be an autonomous and self dependent for the power, it generates power from solar panels and location information, time tags from the GPS. Though general data acquisition systems are available in the market, they may be expensive or cultivated in acquiring the data. The data logged onto a thumb drive which is a plug and play device.

\section{PROBLEM STATEMENT}

The issue has to do with solar energy and changing fast weather conditions. Owing to the earth's relentless motion, the fixed solar panels do not point directly at the sun. As a consequence, the system does not generate the full amount of power it can. Solar monitoring device is a better option for this system to get the full output power. This is the primary reason for the development of the project solar tracker. To maximise production power, the solar tracker will follow the sun. It would indirectly lower the cost of purchasing a large number of solar panels. These systems often will the time it takes for users to adjust the solar panel's orientation to face the sun. The weather station are shows very fast changing weather forecast in atmosphere. The weather station are helpful to agriculture sector. 


\section{PROPOSED WORK}

The system is divided into two parts: the solar tracking system and the weather forecast. The sensor circuit, the microcontroller, the display unit, and the GSM are the main components of the weather prediction part. The temperature, humidity, leaf moisture and humidity sensors are part of the sensor circuit. One sensor outputs analogue data, which is converted to digital data by the controller's ADC, and another sensor outputs digital data, which is then analysed to obtain temperature and humidity. The calculated parameters will appear on an LCD monitor. Figure 1 depicts a block diagram of the overall structure. Our telephone is in the collector territory. Everything is coming from the climate station to our telephone.
The nucleus of our system is the core component of this system. The arduino is used in the central portion. We use ADC to connect various types of sensors to the arduino and GSM and LCD are also connected to the auduino.

The sensor in this project detects the weather and sends data to our phone. Temperature, humidity, moisture and sensors are all related. This reading is sent to our phone via GSM. Every 30 minutes, the Raspberry Pi saves the data and sends it to our mobile phone after 4 hours. Using this information, a farmer can quickly determine which spray is needed for a grape farm.

\section{SYSTEM ARCHITECTURE:}

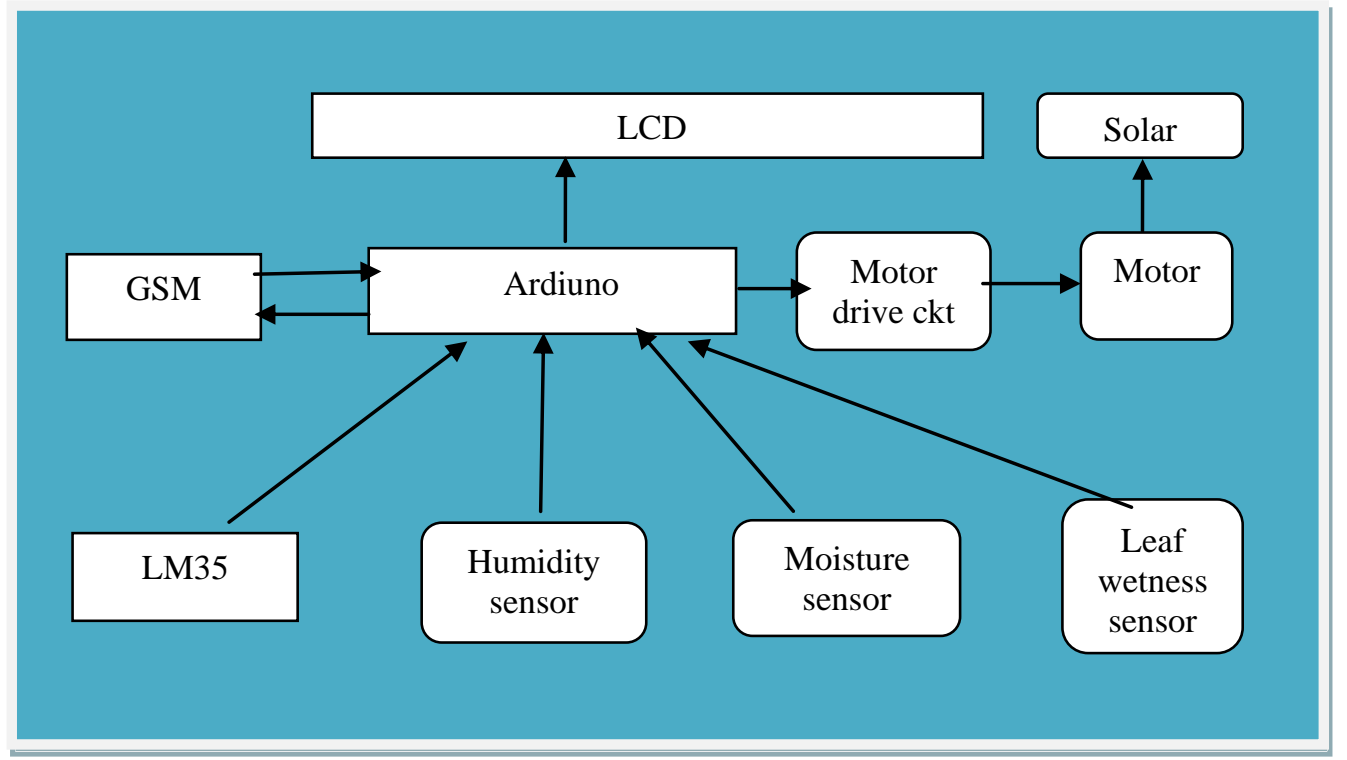

Fig. 1. Block diagram of Solar operated weather forecasting station

\section{SYSTEM REQUIREMENTS:}

- LCD

- Arduino

- GSM

- Motor drive circuit

- Motor

- Solar panel

- LM35 sensor

- Humidity sensor

- Moisture sensor

- Leaf wetness sensor

\section{WORKING:}

This project aims to look at how well a single-axis solar tracking device works. The inputs, controller, and output are the three fundamental structures that make up this system. Where LDRs act as inputs, Arduino serves as controller. The stepper motor is operating to change the angle of the solar panel to extract maximum power. Arduino receives analogue information from the LDRs and converts it to a digital signal using an analogue-to-digital (A-D) converter in this system. It has powered by a battery that charges through solar energy. The controller then sends an alert to the stepper motor, which determines the solar panel's movement. The temperature sensor used to detect the temperature of the ambient atmosphere. Humidity is measured in the atmosphere using a humidity sensor. A moisture sensor detects moisture in the air. In steady panel system; the sun angle varies in response to a solar signal or solar radiation, a significant amount of energy lost. Therefore, a solar tracking system results in improved productivity. The sensors detect the weather and display it on a digital display, and all of the sensing parameters sent to an Android phone via the GSM module. The data from the Arduino kit has forwarded to the GSM module. With the aid of various sensors, we can analyse the data every hour.

1) LM35 Temperature Sensor is used to:

- Measuring temperature in particular environment

- Providing thermal shut down for a circuit

- Monitoring Battery Temperature

2) Leaf Wetness Sensor is used to:

- To predict when to spray crops.

- To quantify water storage in the plant canopy. 
- In studying and monitoring crops for foliar diseases including rust and blight.

3) Humidity sensors is used to:

- Is also found as part of home heating, ventilating and air conditioning systems. These are also used in offices, cars, humidors, museums, industrial spaces and greenhouses and are also used in meteorology stations to report and predict the weather.

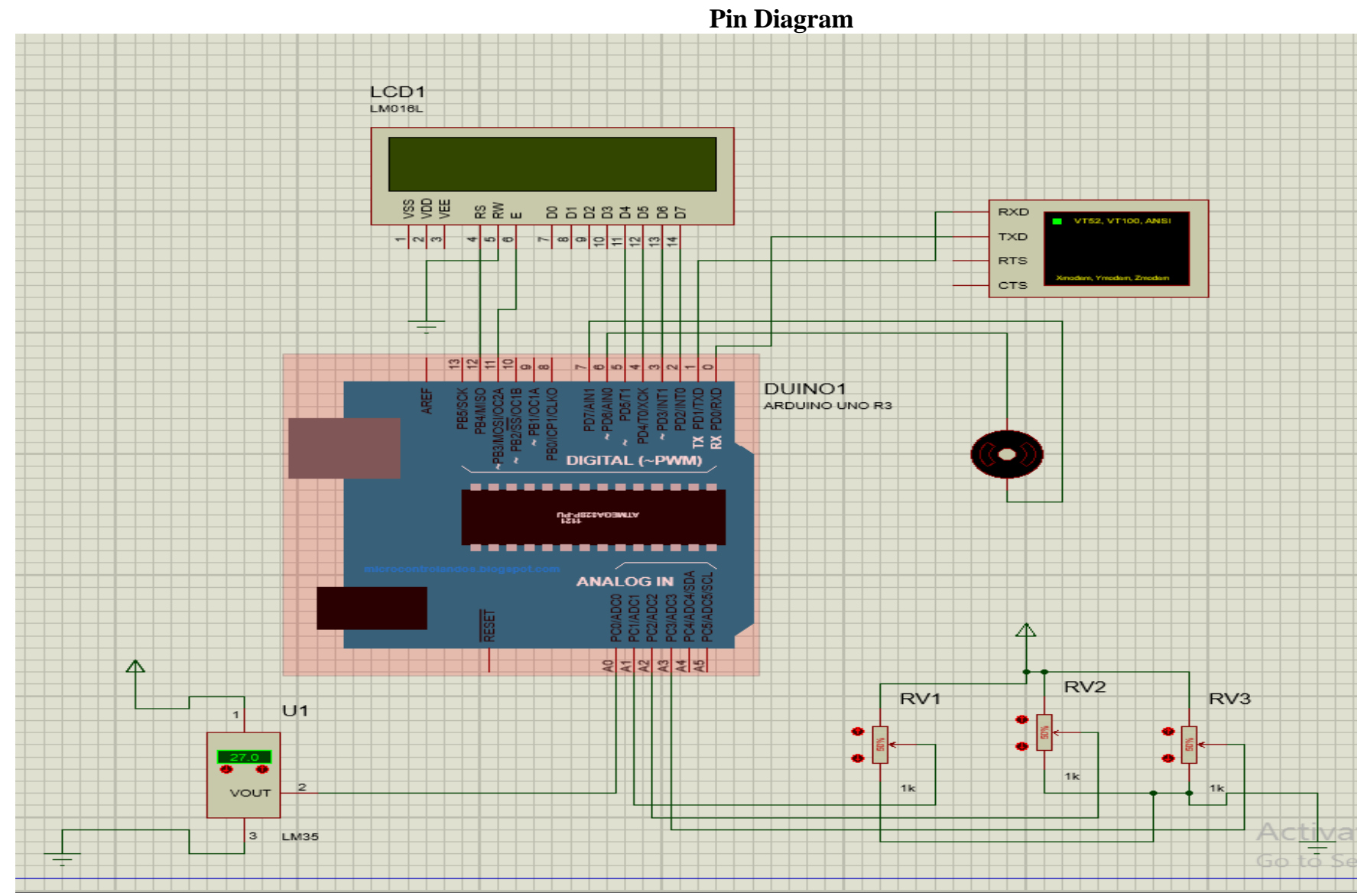

Fig. 2. Pin diagram of Solar Operated weather forecasting station
4) Moisture sensor used to:

- Landscape irrigation

- Research
- Agriculture

Pin Diagram

VII. RESULT

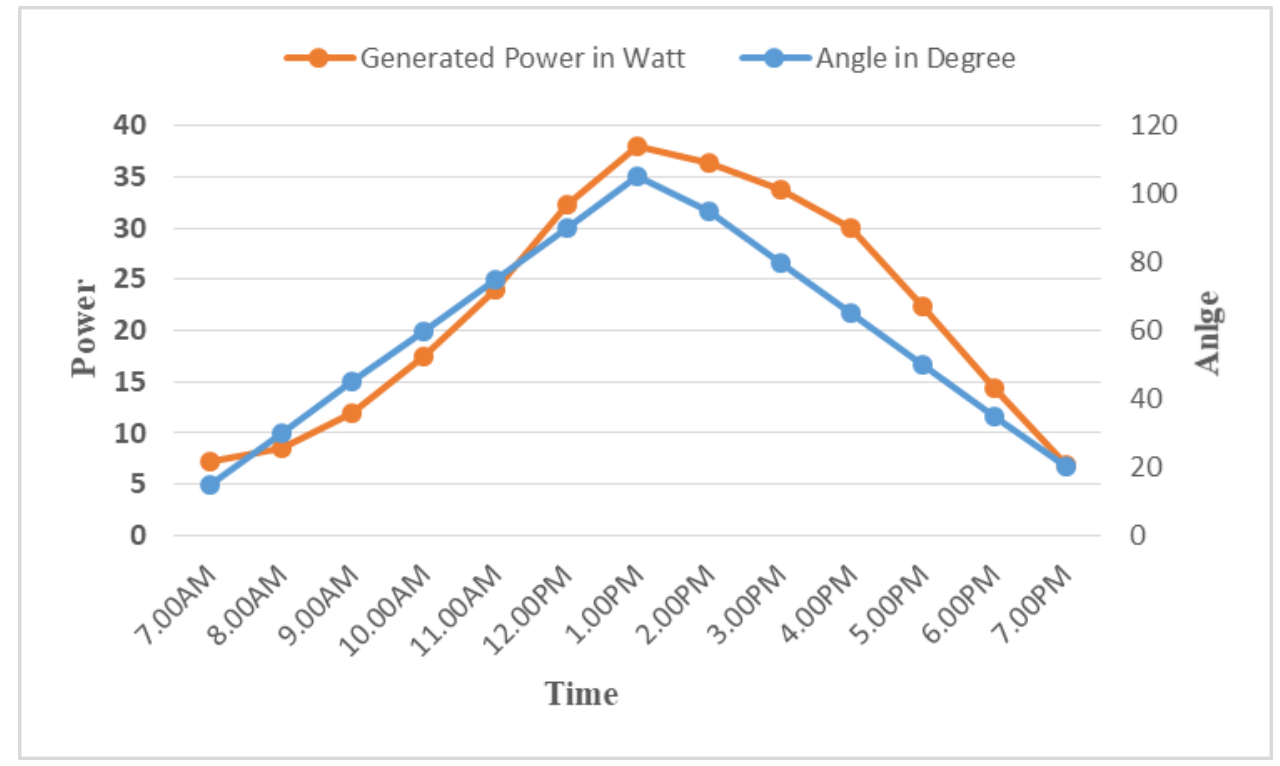

Fig. 3. Generated solar energy with Solar tracking system. 
The above fig.3.shows that the results of generating solar energy to direct sun radiations with help of the solar tracking system. The solar generating plant are starts at after the sun rise and this time solar trackers are move to the sun directions. The solar trackers are track the sun by per hour

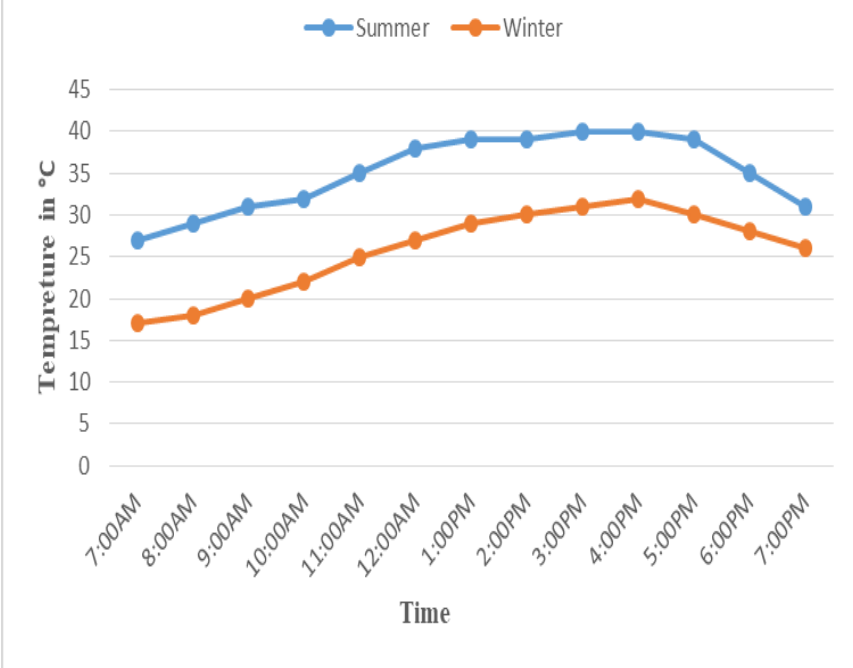

(a)

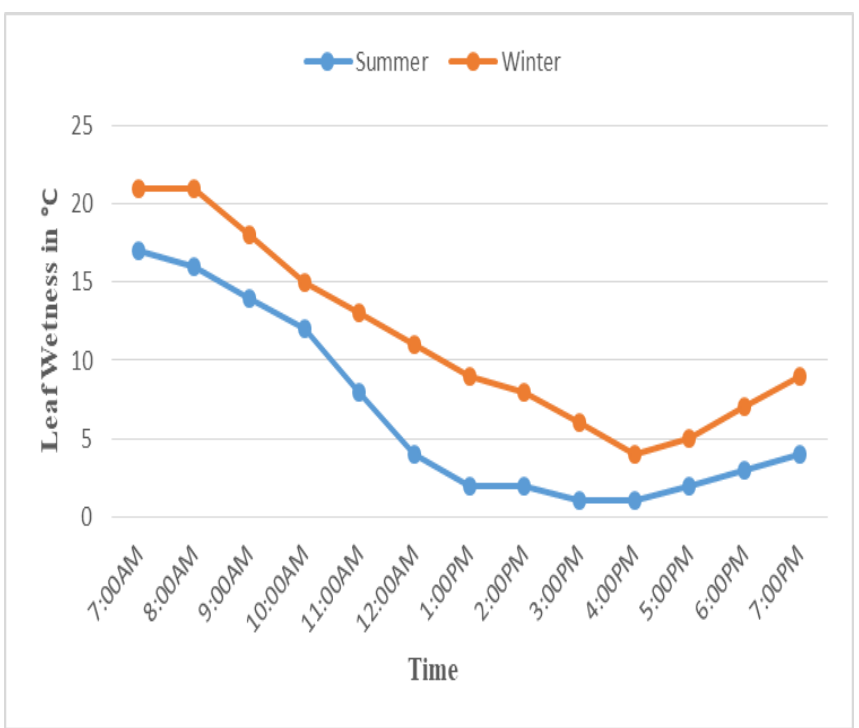

(c)

Fig. 4. Weather Forecast performing analysis in summer and winter conditions

The simulation experiments conducted for two days in two weather conditions; the first weather Condition is a summer condition. In this summer condition, measurements have collected by date is 28 March 2021 . This day was the hottest day of this month. The measure has taken on a few types of sensor means temperature sensor, humidity sensor, leaf wetness \& moistures sensor. These sensors are measurement taken by hourly weather conditions on this day.

The 2 nd weather condition is winter conditions. In this winter condition, measurements have collected on 24 December 2020. Fig. - is showing that in winter, the temperature is ordinaryly low \& leaf wetness increases. In this condition, solar energy is min produces as compare to summer condition. These measurements are a display of LCD on simulation. All results are sent on the Android module by the GSM module. These results are collected hourly on one day \& the solar trackers track the sun with angle of $15^{\circ}$. Power of the system is measured in per hourly. In our observation the solar tracking system are increasing the efficiency of generating solar energy as compare to steady solar system.

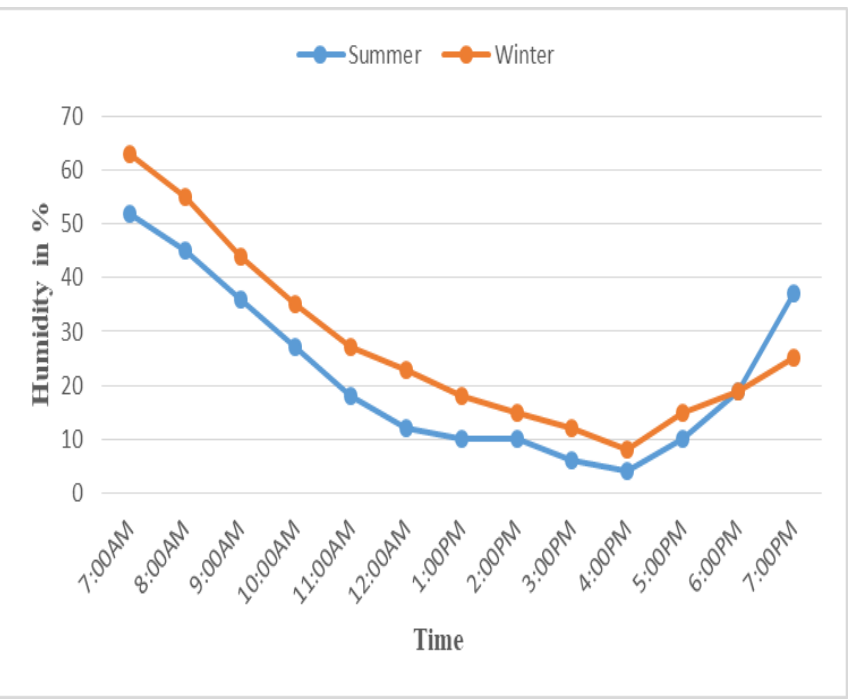

(b)

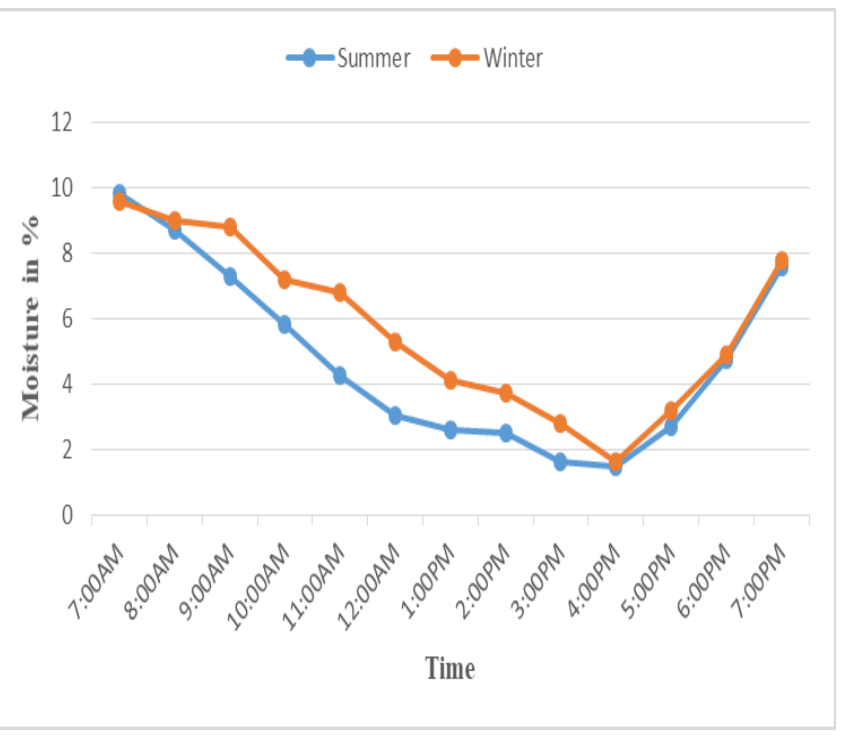

(d)

respectively $15^{0}$ per hour. This all measurements are showed in above fig.4.

\section{CONCLUSION}

The performance of a single-axis solar tracking device has investigated. According to the Weather station, the single-axis solar tracking device outperforms the static solar panel in output voltage, current, and power. As a result, the device successfully collects the total amount of sunlight for solar harvesting applications. A friendly single-axis solar tracking device can also be a perfect way to take advantage of solar energy's dominance while also addressing rising electricity demand. A weather station is a system that monitors all of the weather conditions in nature. It is particularly beneficial to the agricultural sector. 


\section{REFERENCES}

[1] Sebastijan Seme, Bojan stumberger, Miralem Hadziselimovic, Klemen Sredensek. "Solar photovolatic tracking systems for electricity generation:A Review”, Energies 13:4224, August 2020.

[2] Midriem Mirdanies, Roni Permana Saputra "Dual-axis solar tracking system: A combined astronomical estimation and visual feedback", 2016 International Conference on Sustainable Energy Engineering and Application (ICSEEA), October 2016.

[3] Anurag Singh, Sagarika Kundu, Nishant Shukla, Sanjay Gupta "IoT based Weather Monitoring System using Sun Tracking Solar Panel”, International Journal of VLSI Design and Technology, Vol 1, No 1 (2019)

[4] Nurzahigit Kuttybay, Ahmet Saymbetov, Saad Mekhilef, Madiyar Nurgaliyev, Didar Tukymbekov, Gulbakhar Dosymbetova, Aibolat Meiirkhanov, Yeldos Svanbayev. "Optimized Single-axis schedule solar tracker in different weather conditions", Energies 13:5226, October 2020.

[5] Divya V \& Sashanka, P."Renewable Energy”. Retrieved June 5, 2012, Yuva Engineers, April 30, 2010.
[6] Asmarashid Ponniran, Ammar Hashim, Ariffuddin Joret. "A Design of Low Power Single Axis Solar Tracking System Regardless of Motor Speed".Internal Journal Of Intergrated Engineering,Vol.3 No.2(2011) p 5-9

[7] J.Beltran A.,J.L Gonzalez Rubio S.y C.D.GarciaBeltran"Design,Manufacturing and Performance Test of a Solar Tracker Made By a Embedded Control. Fourth Congress of Electronic, Robotic and Automotive Mechanics"

[8] [O.C.Vilela, N.Fraidenraich\& C.Tiba, (2003) "Photovoltaic pumping systems driven by tracking collectors. Experiments and simulation Figure 12 shows the graphs of output power comparison between the static panel and the tracker for day 2. For the solar tracker, the highest output power produced was $0.94 \mathrm{~W}$ at $12.45 \mathrm{p} . \mathrm{m}$ while the lowest output power was 0.08W at2003) Solar Energy, 74 (1), pp. 45-52

[9] A.K. Saxena \& V. Dutta, "A versatile microprocessor- based controller for solar tracking”, IEEE Proc., 1990, pp. 1105 - 1109.

[10] A.Yazidi, F. Betin, G. Notton \&G. A. Capolino, "Low cost two-axis solar tracker with high precision positioning", Proceedings of 6.00p.m. As for the static panel, the highest and the lowest output power produced were $0.94 \mathrm{~W}$ and $0.06 \mathrm{~W}$ respectively, July 2006. 